político, el servidor, criado o barbero, heredará esta función -pasamos de El burlador de Sevilla a El barbero de Sevilla, de la relación con Dios, a la relación con los hombres.

En el último Barroco, el gracioso ya empieza o a encarnar simbólicamente su esencia religiosa o a sustituirla por una inteligencia mundana. Recuérdese que también en el último Barroco se prefiere al villano noble el noble disfrazado de villano.

New York University.

Joaquín Casalduero

\title{
SOBRE UN SONETO DE GUTIERRE DE CETINA
}

En su artículo "Color symbolism in early Spanish ballads", $R R Q$, 6 (1915) , 327-340, H. A. KenYon afirma que en el soneto de Cetina "Es lo blanco castíssima pureza..." tenemos la mejor y más completa exposición del simbolismo de los colores en la poesía castellana (p. 338). En efecto, todo el mérito del soneto consiste en el abundante catálogo de los colores y de sus significaciones simbólicas, y su importancia es capital por lo que se refiere a la historia de ese tema en España ${ }^{1}$.

Conviene reproducir el soneto para ver las afinidades que hay entre él y otros de la misma época casi desconocidos hasta hoy por los investigadores. Es el Soneto 203 en la ed. de Hazañas y La Rúa, Sevilla, 1895:

Es lo blanco castíssima pureza; amores significa lo morado; crueza o sujección lo encarnado;

4 negro oscuro es dolor, claro tristeza;

naranjado se entiende que es firmeza; rojo claro es vergüenza, y colorado alegría; y si obscuro es lo leonado, congoja; claro es señoril alteza;

1 Extraña que al lado de ese soneto no se haya utilizado el Cancionero llamado Dança de galanes (Barcelona, 1625; reprod. por la Hispanic Society, New York, 1903), con sus "Otras muchas canciones sobre diversas colores y las significaciones dellas". He aqui sus rúbricas:

"Si sale la dama de color morado, denota amor";

"Si sale la dama de amarillo, denota desesperación";

"Si sale la dama de negro, denota honestidad o tristura";

"Si sale la dama de blanco, denota castidad";

"Si sale la dama de colorado, denota osadía";

"Si sale la dama de verde escuro, denota esperança dudosa";

"Si sale la dama de azul, denota celos";

"Si sale la dama de leonado, denota grauedad y firmeza";

"Si sale la dama de pardo escuro, denota trabajo";

"Si sale la dama de burel, denota lealtad";

"Si sale la dama de encarnado, denota crueldad";

"Si sale la dama de naranjado, denota despedida";

"Si sale la dama de guarnición de plata, denota señoría";

"Si sale la dama de guarnición de oro, denota magestad";

"Si sale la dama de verde, denota esperança". 
es lo pardo trabajo; azul es celo; turquesado es soberbia, y lo amarillo es desesperación; verde, esperanza.

Y desta suerte, aquel que niega el cielo licencia en su dolor para decillo, 14 lo muestra, sin hablar, por semejanza.

Sorprende el gran parecido entre este poema y un soneto inédito de Eugenio de Salazar, contemporáneo de Cetina, en el f. 212 de su Silva de poesia, ms. conservado en la Academia de la Historia de Madrid:

Denota fe lo blanco, y su pureza; un vivo amor nos muestra lo morado; venganza y alegría el colorado; lo vil negro dolor, lo otro firmeza;

captiverio encarnado, y gran crueza; apunta cumplimiento el naranjado; congoxa, si es escuro, lo leonado, y cuando es claro, señorío y alteza; trabajo al corazón nota el pardillo; la zelosía en el azul parece, y desesperación en lo amarillo; en verde la esperanza reverdece, soberbia en turquesado. El corazón 14 assí sin hablar muestra su passión.

Es evidente, pues, que el soneto de Cetina carece de originalidad; pero en cambio introduce algunas mejoras en cuanto a la expresión y la forma, especialmente en los tercetos. Son dos las principales divergencias. Cetina dice que el rojo claro significa vergüenza y el "colorado" alegría, mientras que, según Salazar, el colorado tiene el doble significado de venganza y alegría. Para Cetina, el negro claro es tristeza; para Salazar ("lo otro"), es firmeza. La diferencia en la interpretación del "naranjado" (v. 5 en Cetina, 6 en Salazar) es más aparente que real, pues firmeza y cumplimiento son casi lo mismo.

Sobre el modelo inmediato de Salazar no hay duda: él mismo escribe en la Silva (f. 211) que su soneto es traducción de un "soneto de autor incierto en lengua toscana", del cual nos ofrece una copia incorrecta y desaliñada:

Candida e pura fede il bianco apreza, vivace amor significa il morato, e servitu soieta lo incarnato; il vil negro dolor, gli altro fermeza;

vendetta il russo chiar et alegreza; dinota compimento l'indorato; angoscia quando è bruno lo lionato, si ̀̀ chiaro signoria, et alteza;

travaglio sempre al cuor dice il pardiglio;

ne lo azurro zelossia rinverde, et desperacion dice il mariglio;

speranza si dinota in chiascun verde; torchin superbia. E cossi il cuore senza parlar scuopre il suo dolore. 
Los españolismos que se encuentran en este poema hacen suponer que su autor fuese un español o por lo menos un italiano españolizado. Naturalmente, reaparecen en él las afinidades y divergencias que hemos notado entre Salazar y Cetina, pero hay dos pequeños detalles en que coinciden Cetina y el anónimo: por una parte la expresión rojo claro $=$ russo chiar, y por otra la colocación del tercer verso. Sin embargo, la doble significación del encarnado en Cetina ("crueza o sujección") delata su derivación salazariana (v. 5, "captiverio... y gran crueza").

La fuente del anónimo poema italiano es probablemente este soneto atribuído a Serafino Aquilano, poeta prebarroco bastante popular entre los españoles durante el Renacimiento ${ }^{2}$ :

Si come el verde importa speme o amore, vendetta el rosso, el turchin gelosia, fermeza el negro e anchor malinconia; el blanco mostra purità di core;

el giallo haver extinto ogni suo ardore, e chi veste morel secreto sia; taneto poi fastidio e fantasia, el beretin travaglia pene e errore.

En questo ultimo volsi a te venire, abito conveniente a chi mi manda, perchè vedesti quel che non può dire.

E senza fine a te se racomanda, ne ti priega altro fin al suo servire, che chi ben serve e tace assai dimanda.

Todos los colores contenidos en la armazón del soneto están subordinados a uno, el beretin, llevado por su autor para revelar la pena que no puede declarar abiertamente. Lo mismo ocurre en las composiciones arriba citadas, en las cuales la enumeración de colores sirve para dar relieve a uno que manifiesta, sin hablar, el dolor del amante. Un enlace verbal entre Si come el verde..., el anónimo y Salazar puede observarse, además, en la significación del negro.

Falta todavía decir algo sobre la discrepancia entre "Es lo blanco..." y los demás sonetos en cuanto a lo simbolizado por el rojo. Como rojo $=$ venganza es la denotación común que se da en los tratados sobre el asunto, mientras que rojo = vergüenza es muy raro ${ }^{3}$, es posible concluir que el copista de los poemas de Cetina escribió por descuido vergüenza en vez de venganzat. La prueba nos la dan otras dos versiones de "Es

2 Serafino Aquilano, Rime, ed. Menghini, Bologna, 1894, p. 218. Como indica allí mismo Menghini, el verdadero autor es Niccolò da Correggio.

${ }^{3}$ Cf., por ejemplo, Trattato de' colori di M. Coronato Occolti da Canedolo, Parma, 1568; Opera nuova chiamata Pantheon, Venetia, 1533; Il mostruosissimo mostro di Giovanni de' Rinaldi, Venetia, 1602. Rojo=vergüenza tampoco tiene el apoyo de la tradición española, como lo demuestran los estudios de KenYon, art. cit.; S. G. MorLey, "Color symbolism in Tirso de Molina", $R R Q, 8$ (1917), 77-81; W. L. Fichter, "Color symbolism in Lope de Vega", $R R Q, 18$ (1927), 220-231; B. MatulKa, "Fiometa's sepultura. Color symbolism", en The novels of Juan de Flores and their European diffusion, New York, 1931, pp. 266-282; y el ya citado Cancionero llamado Dança de galanes.

${ }^{4}$ El soneto que nos ocupa fué tomado por Hazañas y La Rúa de un códice perteneciente a don José María de Alava, de Sevilla, intitulado Todas las poesias de Gutierre 
lo blanco...", que se encuentran respectivamente en el Cartapacio de Pedro de Penagos, de 1593 (Bibl. de Palacio), y en una antología de poetas españoles de la Bibl. Riccardiana de Florencia (ms. 3.3358, f. 113); en el primero de estos códices el v. 6 dice: "rojo claro vengança, y colorado..."; y en el segundo: "rojo claro es vengança, y colorado..."5. Verdad es que una tercera versión de "Es lo blanco...", la del ms. 3913 de la B. N. M., f. 31 . $\mathrm{r}^{0}$, coincide casi exactamente en el v. 5 con la versión del códice de Álava ("rojo claro vergüenza...") ${ }^{6}$. Con todo, fundándome en los argumentos ya aducidos, sigo creyendo que la lección "rojo claro es venganza" es más convincente. La versión del ms. 3913 provendrá directa o indirectamente del códice de Álava, con la añadidura de algunos cambios arbitrarios hechos por el nuevo copista.

Northwestern University.

JOSEPH G. Fucilla

de Cetina, sacadas de su propio original que él dexó de su mano escrito. Parte primera. Sobre esa copia dice Hazañas (t. I, p. lxiv): "El manuscrito está lleno de incorrecciones, falto de sílabas y aun de palabras en unos versos, sobrado de ellas en otros, y conteniendo voces que evidentemente no son las que el autor escribió, razón por la cual se notan variantes de importancia entre las poesías contenidas en este códice y algunas de las publicadas, cuyos correctores las corrigieron".

${ }^{5}$ La versión del Cartapacio fué publicada por J. DE Entrambasaguas, "Poesías nuevas de Lope de Vega en parte autobiográficas", RevBAM, 11 (1934), p. 23 de la separata. Otras variantes (prescindiendo de las puramente ortográficas): 3 o sujeción es lo encarn.; 4 negro es crudo d.; 7 y si escuro lo morado; 8 congoja, y si es claro anuncia alteça; 10 turquesado, soberbia; 12 De suerte que ya que diese el cielo; 13 en el dolor; 14 bien se puede mostrar por semejanza. - Otras variantes del ms. de la Riccardiana: 3 crueldad o sujección es; 4 negro claro es dolor, escuro tr.; 5 n. se dice que; 7 alegría, y escuro leonado; 8 c., y el claro s. a.; 9 pardo es t., el azul es zelo; 10 turquesano; 11 [es]; 12-13 Desta manera aquel che fuerça el cielo / a callar su dolor y no encubrillo...

- Ignorando que ya estaba impresa en la $B A A E E$, t. 69 , pp. $49^{\circ-491}$ (con atribución equivocada a Quevedo), publicó esta versión como inédita ERASMo BUcETA, "Un soneto del siglo xvi explicativo del simbolismo de los colores", en $\mathrm{BHi}, 35$ (1933), 299-300. Variantes: 3 crudeza o sugeción es lo e.; 4 n. claro es dolor, escuro tristeza; 7-8 furor; vayo desprecio, leonado / congoja; claro muestra ser alteza; $12 \mathrm{Y}$ desta suerte a quien le negó el cielo; 13 licencia en el d.; 14 puédese aquí mostrar por semejanza. 